\title{
Internal fit of two all-ceramic systems and metal- ceramic crowns
}

\author{
Leandro Moura MARTINS ${ }^{1}$, Fabio Cesar LORENZONI², Alcides Oliveira de MELO ${ }^{3}$, Luciana Mendonça da SILVA ${ }^{1,2}$, \\ José Luiz G. de OLIVEIRA ${ }^{4}$, Pedro Cesar Garcia de OLIVEIRA ${ }^{5}$, Gerson BONFANTE ${ }^{5}$
}

1- Professor, School of Dentistry, Federal University of Amazonas, Manaus, AM, Brazil.
2- PhD student, Department of Prosthodontics, Bauru School of Dentistry, University of São Paulo, Bauru, SP, Brazil.
3- Undergraduate student, Bauru School of Dentistry, University of São Paulo, Bauru, SP, Brazil.
4- MSc student, Department of Prosthodontics, Bauru School of Dentistry, University of São Paulo, Bauru, SP, Brazil.
5- Professor, Department of Prosthodontics, Bauru School of Dentistry, University of São Paulo, Bauru, SP, Brazil.

Corresponding address: Leandro de Moura Martins - Faculdade de Odontologia de Bauru - USP - Departamento de Prótese - Alameda Octávio Pinheiro Brizolla, 9-75 - 17012-101 - Bauru - SP - Brazil - Fax: 55-14-3235-8231 - e-mail: martins.I.m@gmail.com

Received: July 08, 2010 - Modification: September 21, 2010 - Accepted: October 26, 2010

\section{ABSTRACT}

\begin{abstract}
bjectives: The aim of this study was to investigate the internal fit (IF) of glass-infiltrated alumina (ICA - In-Ceram Alumina), yttria-stabilized tetragonal zirconia polycrystals (Y-TZP - IPS e.max ZirCAD), and metal-ceramic (MC - Ni-Cr alloy) crowns. Material and Methods: Sixty standardized resin-tooth replicas of a maxillary first molar were produced for crown placement and divided into 3 groups ( $n=20$ each) according to the core material used (metal, ICA or Y-TZP). The IF of the crowns was measured using the replica technique, which employs a light body polyvinyl siloxane impression material to simulate the cement layer thickness. The data were analyzed according to the surfaces obtained for the occlusal space (OS), axial space (AS) and total mean (TM) using two-way ANOVA with Tukey's multiple comparison test $(p<0.05)$. Results: No differences among the different areas were detected in the MC group. For the Y-TZP and ICA groups, AS was statistically lower than both OS and TM. No differences in AS were observed among the groups. However, OS and TM showed significantly higher values for ICA and Y-TZP groups than MC group. Comparisons of ICA and Y-TZP revealed that OS was significantly lower for Y-TZP group, whereas no differences were observed for TM. Conclusions: The total mean achieved by all groups was within the range of clinical acceptability. However, the metal-ceramic group demonstrated significantly lower values than the all-ceramic groups, especially in OS.
\end{abstract}

Key-words: Crowns. Dental adaptation. CAD-CAM.

\section{INTRODUCTION}

Although the metal-ceramic system is still widely used to fabricate crowns and fixed partial dentures (FPDs) ${ }^{14}$ and is considered as the standard treatment in dentistry ${ }^{7}$, aesthetic concerns have stimulated the development of new dental ceramic systems ${ }^{33}$. The ongoing search for ceramic materials with mechanical properties suitable for use in highload areas has resulted in the development of new ceramics with high strength (alumina and zirconia) ${ }^{7}$. At present, ceramics are the materials of choice for crowns and FPD due to their superior aesthetic and biocompatibility features ${ }^{19}$.

In addition to the development of ceramic materials, new processing technologies have been introduced for the production of all-ceramic cores ${ }^{11}$. In contrast to the conventional technique (lost wax) employed to produce the metal core, all-ceramic cores are fabricated from heat-pressed, slip-cast, CAD/CAM (computer-assisted design/computerassisted machining), and CAM technologies, which employ many ceramic-based materials ${ }^{3}$. The slip-cast (e.g., alumina ceramic-based) is a hand-building technique that requires a duplication of the stone die to the stone refractory prior to fabrication of the alumina core. The CAD/CAM technique employs sophisticated technologies, and the core can be fabricated from densely sintered or partially-sintered ceramic blocks. A scanner digitalizes the prepared tooth, and the framework or a restoration is then fabricated according to the 
previously established design. Additionally, CAD/ CAM systems have been developed to eliminate or minimize potential sources of errors present in conventional manufacturing techniques ${ }^{24}$.

The performance of the all-ceramic crown system is complex and depends on many factors, including those controlled by the clinician and those that are patient-dependent ${ }^{21}$. The shape and thickness of the core and veneer porcelain, laboratory processing methods, elastic modulus of the restoration components, and framework design are conditions that are speculated to play a role in prosthesis longevity ${ }^{20,30}$. Moreover, this crown-cement system should be considered a single structure comprising layers of materials with different mechanical properties. Recently, a three-dimensional finite element model of a molar crown showed that the combination of different material layers and load conditions could produce negative effects on the maximum principal stress in the core ${ }^{18}$.

The internal fit (IF) is a clinically relevant topic and can affect the strength of a crowncement system ${ }^{19}$. The IF should be uniform to avoid compromising either the retention or the resistance of the crown and should also provide an appropriate luting space ${ }^{13}$. Dental cements are used to maintain the position of the restoration for long periods; however, some factors seem to influence the seat during the cementation procedure, such as the height and convergence of the axial walls, the diameter of the preparations, the presence of retentive channels and the type of cement used ${ }^{5}$. This set of factors can explain the difficulties associated with cement flow and the oblique seating of the crowns ${ }^{6}$.

Considering that most of the previous investigations did not separate the IF into different regions (occlusal and axial spaces) ${ }^{2,31}$ and the small number of studies comparing the IFs of all-ceramic systems to that of metal-ceramic, we sought to examine the in vitro IF (occlusal, axial, and total mean) of a posterior all-ceramic single crown after simulation of the cementation procedure using a silicone-based material. Two null hypotheses were tested: 1- there were no differences between occlusal, axial and total mean measurements within each group; 2 - there were no differences in IF among the groups.

\section{MATERIAL AND METHODS}

An artificial maxillary first molar was positioned in a full mouth dental model and manually prepared for a complete crown. The preparation comprised a $1.2 \mathrm{~mm}$ circumferential chamfer at the gingival margin, $2.0 \mathrm{~mm}$ of occlusal reduction, and $1.5 \mathrm{~mm}$ of axial wall reduction. The angle of convergence was approximately $8^{\circ}$, and all of the sharp angles were rounded and smoothed (Figure 1). The prepared tooth underwent six impression using vinyl polysiloxane material (Express; 3M ESPE, St. Paul, MN, USA), to which small increments of the composite resin (Filtek Z100; 3M ESPE) were added until the final composite shape was acquired, resulting in sixty standardized composite resin tooth replicas. The replicas were randomly divided into three groups ( $n=20$, each) according to the core material: group 1 (control) - metal-ceramic (MC, Nickel-chromium, AlbaDent, Cordelia, CA, USA), group 2 - slip-cast alumina (ICA, InCeram, VITA Zahnfabrik, Bad Säckingen, Germany), and group 3 - CAD/CAM (Y-TZP, IPS e.max ZirCAD, Ivoclar Vivadent AG, Schaan, Liechtenstein).

An impression of each replica was obtained using polyether material (Impregum F; 3M ESPE). Subsequently, these moulds were poured with stone (Durone, Dentsply Ind. Com. Ltda, Petrópolis, $\mathrm{RJ}$, Brazil), resulting in 60 stone dies. Die spacing was not used. The stone dies were then sent to a commercial dental laboratory.

\section{Crown fabrication}

All materials were used according to manufacturer's instructions. The metal cores were conventionally fabricated (lost wax technique) and cast. The investment was removed from the framework and cleaned by $110 \mu \mathrm{m}$ aluminum oxide sandblasting. ICA cores were fabricated using the slip-cast technique. Prior to fabrication of the frameworks, the stone dies were duplicated with special silicone and poured with a refractory stone. A slurry of densely packed $\mathrm{Al}_{2} \mathrm{O}_{3}$ was applied to a surface of the refractory die, followed by sintering

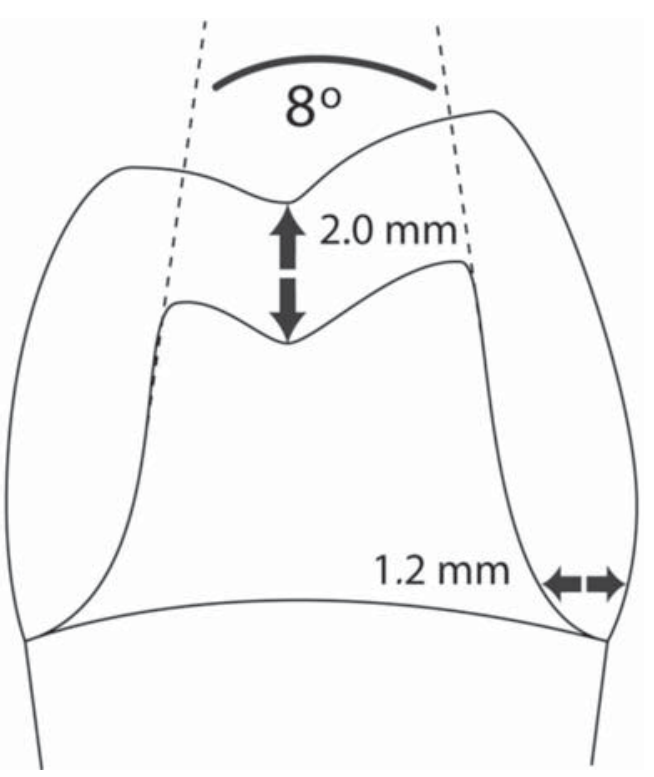

Figure 1-Schematic representation of the prepared tooth and measurements 
for $10 \mathrm{~h}$ at $1,120^{\circ} \mathrm{C}$ in a special furnace. The porous core was then infiltrated with lanthanum glass in a second firing cycle at $1,100^{\circ} \mathrm{C}$ for $2.5 \mathrm{~h}$, and the cores were then sandblasted with $110 \mu \mathrm{m}$ aluminum oxide to remove excess lanthanum glass from the core surface.

Y-TZP cores were fabricated using a milling technique with CAD/CAM system CEREC InLab (Sirona, Bensheim, Germany). Optical impressions were obtained using a charge-coupled device (CCD) camera, which generated a 3D image of each stone die. A negative cement space $(-30 \mu \mathrm{m})$ was chosen before milling crowns. Cores were then milled from pre-sintered e.max ZirCAD blocks (block size of 15C) and sintered in a Sintramat (Ivoclar Vivadent AG) furnace at $1,500^{\circ} \mathrm{C}$ for $8 \mathrm{~h}$. This technique results in an enlarged core that achieves its final dimensions after a linear shrinkage of $20-25 \%$ during the sintering process ${ }^{15}$. Internal adjustments were not required for any of the crowns.

The veneer porcelain was manually layered on the frameworks, where this process was guided by the silicone matrix of the maxillary first molar. Each ceramic system required a specific porcelain veneer according to its thermal expansion coefficient. For MC, the feldspatic porcelain veneer Vita VMK 95 (VITA Zahnfabrik, Bad Säckingen, Germany) was used, whereas ICA cores were veneered with Vita VM7 (VITA Zahnfabrik, Bad Säckingen, Germany), and e.max Ceram (IPSe.max ZirCAD - Ivoclar Vivadent AG, Schaan, Liechtenstein) was used for Y-TZP cores.

\section{Measurement of the internal fit}

The cement space replica technique ${ }^{9}$ was used to measure the IF. The internal surfaces were cleaned with $70 \%$ alcohol and then dried with air to remove debris. The crowns were carefully coated with a light body silicone (Express; 3M ESPE) and placed on the corresponding tooth resin replica with firm hand pressure followed by the application of a force $(49 \mathrm{~N})$ to the center and parallel to the long axis of the crown for 10 min. A device with a vertical arm was used. The crown was positioned at one end of the arm with a weight of $5 \mathrm{~kg}$ at the top. After setting of the material, the crowns were gently removed, and the thin silicone films typically remained adhered to the tooth replica. Heavy body silicone (Express; 3M ESPE) was used to remove the films, and the light and heavy assemblies were filled with another heavy layer and then sectioned into three regions with a razor blade in the buccal-palatal direction (Figure 2), resulting in two faces to be measured. Measurements were obtained for two regions of interest (occlusal and axial spaces) to better evaluate the results in addition to the total mean (TM). The axial space (AS) consisted of the entire extension of the axial wall (from the chamfer line to the transition of the rounded angle to the occlusal surface). The occlusal surface (OS) included the entire extension of this surface between two rounded transition angles and AS. Nine different points of each slice were measured: 3 occlusal, 3 buccal and 3 palatal, resulting in 54 measurements for each crown (Figure 3). A Toolmaker's Microscope (Mitutoyo, Tokyo, Japan) was used to measure the cement thickness (light body) using a 50x magnification, and all measurements were performed by the same examiner.

\section{Statistical analysis}

The mean measurements were analyzed separately according to surfaces from which they were obtained (OS, AS, and TM) using two-way ANOVA with Tukey's multiple comparison test at a significance level of $p<0.05$.

\section{RESULTS}

Figure 4 shows the means and standard deviations of the film thicknesses in each group and the statistical differences among the groups. The

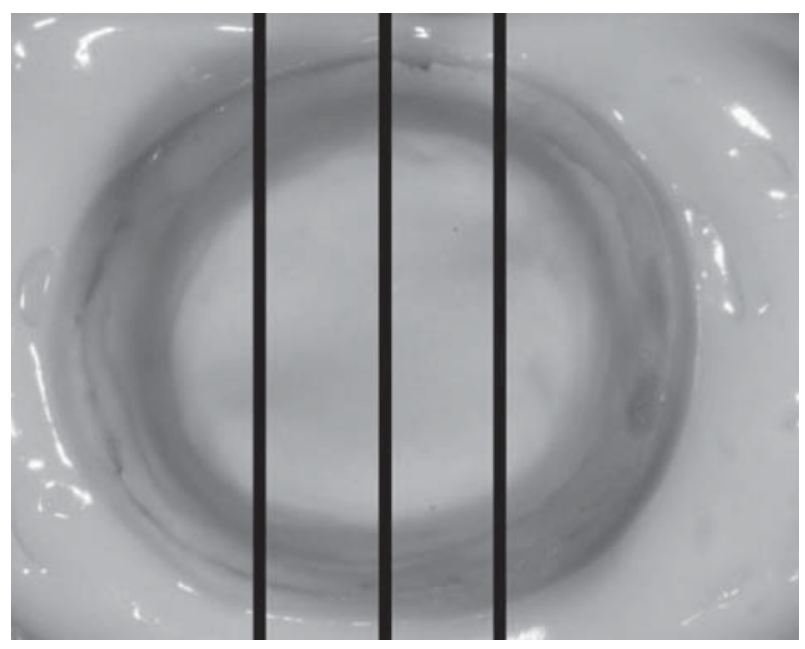

Figure 2 - Occlusal view of the silicone layer on the replica tooth resin prior to embedding with heavy body silicone. The lines indicate the zones where the silicone will be sectioned

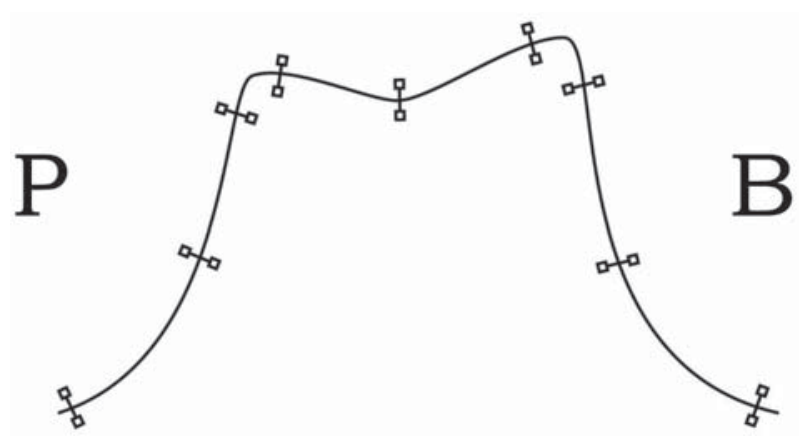

Figure 3 - Positions of the cement line measurements 


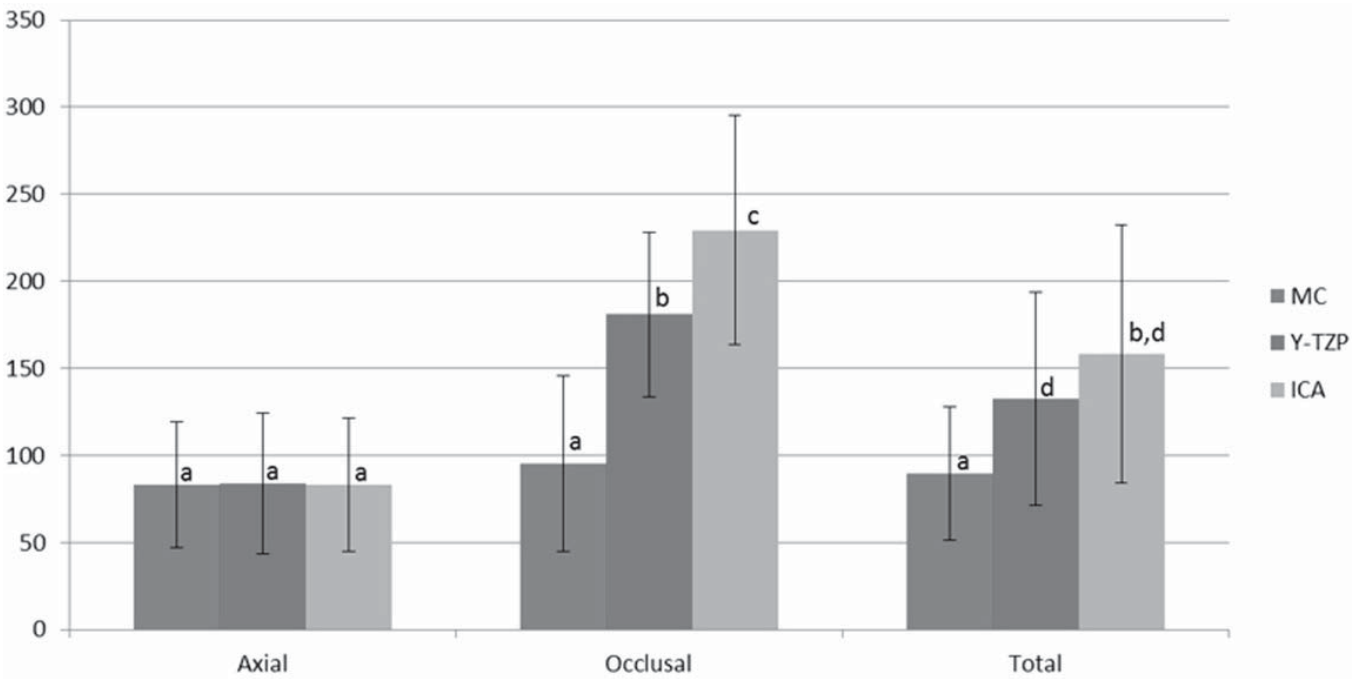

Figure 4 - Means and standard deviations of the internal fit by groups $(\mu \mathrm{m})$. Values with the same letter were not significantly different $(p<0.05)$

maximum deviations for the groups were 222.79 $\mu \mathrm{m}(\mathrm{OS})$ and $139.72 \mu \mathrm{m}$ (AS) for MC group, 246.67 $\mu \mathrm{m}(\mathrm{OS})$ and $112.40 \mu \mathrm{m}$ (AS) for Y-TZP group and $637.01 \mu \mathrm{m}$ (OS) and 152.27 $\mu \mathrm{m}$ (AS) for ICA group. No differences were detected among OS $(95.42 \mu \mathrm{m})$, AS $(83.12 \mu \mathrm{m})$ and TM $(89.76 \mu \mathrm{m})$ in the MC group $(p<0.001)$. For $Y-T Z P, A S(83.93$ $\mu \mathrm{m})$ was significantly lower than both OC (180.90 $\mu \mathrm{m})$ and TM $(132.54 \mu \mathrm{m})(\mathrm{p}<0.05)$. For ICA, AS $(83.14 \mu \mathrm{m})$ was significantly different compared to OS $(229.42 \mu \mathrm{m})$ and TM $(158.27 \mu \mathrm{m})(p<0.001)$. Thus, differences were detected among all surfaces analyzed in both all-ceramic groups.

Among the groups, no differences were observed with respect to AS $(p<0.001)$. The MC group showed significantly lower values for OS compared to ICA $(p<0.001)$ and Y-TZP $(p<0.001)$ groups, and ICA was significantly higher than Y-TZP $(p<0.001)$. For TM, the all-ceramic groups were statistically equivalent, but the value obtained for the MC group was significantly lower than ICA $(p<0.001)$ and Y-TZP $(p<0.05)$.

\section{DISCUSSION}

Crowns and FPD are routinely fabricated using indirect techniques, and are, thus, subject to deformations of the materials. These alterations are somewhat expected and are important for proper seating of the prosthesis onto its abutment tooth. Thus, the space between the internal crown and the prepared tooth surfaces is required to accommodate the cement ${ }^{32}$. IF is a controversial topic in the literature, mainly with respect to its thickness $7,20,21$ and whether it can modify the fracture strengths of crowns ${ }^{19,24,28,29}$. No differences were observed among the measured spaces (OS, AS, and TM) in the MC group, but in the all-ceramic groups, significant differences were detected among these spaces. No significant differences in AS were observed among the groups, but OS and TM showed statistically significant differences. Remarkably, the ICA and Y-TZP groups displayed high values for OS, as compared to the values obtained for the MC group. Moreover, the ICA group differed from $\mathrm{Y}$-TZP group with respect to OS.

Theoretically, the internal space necessary for the cement is 20 to $40 \mu \mathrm{m}^{9}$. An IF ranging between 50 to $100 \mu \mathrm{m}$ has been considered acceptable ${ }^{5}$, but some researchers (without scientific evidence) propose that a cement space ranging between 200 and $300 \mu \mathrm{m}$ is also suitable ${ }^{4,12}$. Rosseti, et al. $^{23}$ (2008) found a lack of significant differences of margin fit values among zinc phosphate, resin composite and resin modified glass ionomer cements. This data indicates that the minimum space is independent of the cement type. In the present study, the smallest IF was observed in the MC group $(89.76 \mu \mathrm{m})$ and the largest in the ICA group $(158.27 \mu \mathrm{m})$. Y-TZP crowns displayed an IF average of $132.54 \mu \mathrm{m}$, which is consistent with the outcomes ( 49 to $136 \mu \mathrm{m}$ ) reported by previous studies evaluating Y-TZP specimens ${ }^{2,31}$. Therefore, all groups presented TMs within the previous recommendations. Only the MC group showed positive results for IF and uniformity. The absence of uniformity of the IF in the Y-TZP group was not expected, because the CAD/CAM technology is used to eliminate potential source of errors ${ }^{24}$, and even choosing a negative value for cement space (-30 $\mu \mathrm{m})$ in order to improve the internal fit, the Y-TZP IF did not provide measures similar to MC IF. Thus, the present results suggest the need to improve the quality of the IF for all-ceramic crowns.

The largest IF is often located at the $\mathrm{OS}^{28}$, which can range in size between 100 and 160 $\mu \mathrm{m}^{29}$. Overall, this value is in agreement with the present findings, although the results obtained for 
ICA $(229.41 \mu \mathrm{m})$ and Y-TZP $(180.90 \mu \mathrm{m})$ exceeded the range of the reported values. A recent study evaluating Y-TZP PFD (without veneer porcelain) demonstrated an average value of $93.2 \mu \mathrm{m}$ for the occlusal space, which differs from the present finding $(180.90 \mu \mathrm{m})^{1}$. The relationship between the fracture strength and the IF in the OS remains unclear. Whereas some researchers have agreed that OS does not influence the crown strength ${ }^{17,28}$, others have stated that a smaller film thickness is preferable, because a greater internal film thickness results in a lower resistance to crown fracture ${ }^{18,32,34}$ and the strength of a crown-cement-tooth system can be dramatically changed when the IF in OS is increased $^{19}$.

Taking into account the positive in vitro and in vivo records for Y-TZP core survival ${ }^{3,26}$ (considering a core thickness of $0.5 \mathrm{~mm}$ ) together with the observation that the cohesive fracture of porcelain is the most important type of failure ${ }^{27}$, one might conclude that IF is not a key factor for the success of the Y-TZP framework. Similarly, due to the ductility of the metal core, the IF is also not an important topic for determination of the success of the MC core. On the other hand, in vivo studies have shown that the most common glass-infiltrate alumina failure for tooth-supported posterior crowns is bulk fracture ${ }^{16}$, because alumina is more susceptible to radial cracks due to surface cementation than is Y-TZP. This contrast between Y-TZP and glassinfiltrate alumina crowns is due to differences in core mechanical properties. Alumina has a strength of $550 \mathrm{MPa}$ and a fracture toughness of $3 \mathrm{MPa} /$ $\mathrm{m}^{1 / 2}$, which are substantially lower than those of Y-TZP (1450 MPa and $5.4 \mathrm{MPa} / \mathrm{m}^{1 / 2}$, respectively). Therefore, the larger IF in OS could be a negative factor for the success of the alumina core, and approaches such as framework modification ${ }^{10}$, cement with a lower elasticity modulus ${ }^{21}$, and tooth substrates with a higher elasticity modulus ${ }^{21}$ should be considered for the clinical success of the veneered alumina crown.

Laboratory processing steps were key factors in the differences observed between the MC and all-ceramic groups, in particular with respect to OS. For the slip-cast technique, high results for all spaces were expected due to fabrication method. In contrast to $\mathrm{MC}$ and $\mathrm{Y}$-TZP cores, the slip-cast technique requires an additional duplication of the master die prior to construction of the core, and this process may have affected the results. Y-TZP demonstrated OS and TM values that were significantly higher than those in the metal-ceramic group. This result was not expected, considering that a CAD/CAM system was used to eliminate potential sources of error that can occur using conventional techniques ${ }^{24}$. Therefore, the occlusal surface seems to be affected by factors that can be speculated as problems related to the accuracy of the optical images acquired, which are not consistently reliable ${ }^{4,24}$. Other explanations could be related to the machining of the Y-TZP blocks such as milling machine, tool-path generation, tool shapes, and sintering processes used to generate the cores and also the tooth preparation design ${ }^{13}$.

Finally, though marginal fit has been associated with marginal gingivitis, occlusal fit may play a significant role on structural durability of allceramic crowns and the axial wall cement space can influence the retention of fixed prostheses ${ }^{25}$. In addition, there is a lack of studies that measure the internal fit and further differentiate the measures of occlusal and axial fit, which hinder any comparison with other studies outcomes ${ }^{22}$. Moreover, the replica technique used in the present study to evaluate the IF of crowns has been extensively used as a non-destructive, reliable and valid method ${ }^{8}$. Further investigations to improve and enhance all-ceramic manufacturing techniques are necessary, and the relationship between the reliability of crowns and the IF could be the topic of future studies by the application of sliding contact fatigue to specimens that simulate the complex geometry of molar crowns.

\section{CONCLUSION}

This investigation showed that metal-ceramic crowns present similar IF, while all-ceramic groups presented differences in IF within the AS and OS regions. Among groups, all-ceramic showed differences in IF compared to metal-ceramic group. Thus, hypothesis 1 , which postulated that within each group IF would be similar in both regions and hypothesis 2, which postulated that there would be no differences in internal fit among the groups, were both partially accepted. The total mean achieved by all groups was within the range of clinical acceptability.

\section{ACKNOWLEDGMENTS:}

We wish to thank Dr. André Inácio Lorenzoni for schematics support; the dental technician José Carlos Romanini for assistance with the preparation, in part, of the specimens; and Prof. Dr. José Roberto Lauris for assistance with the statistical analysis. This study was supported in part by grants from CAPES. The authors are also grateful to CIP-I (Integrated Center of Research - I) for the use of its facilities. 


\section{REFERENCES}

1- Beuer F, Aggstaller H, Edelhoff D, Gernet W, Sorensen J. Marginal and internal fits of fixed dental prostheses zirconia retainers. Dent Mater. 2009;25:94-102.

2- Bindl A, Mörmann WH. Marginal and internal fit of all-ceramic CAD/CAM crown-copings on chamfer preparations. J Oral Rehabil. 2005;32:441-7.

3- Conrad HJ, Seong WJ, Pesun IJ. Current ceramic materials and systems with clinical recommendations: a systematic review. J Prosthet Dent. 2007;98:389-404.

4- Hickel R, Dasch W, Mehl A, Kremers L. CAD/CAM - fillings of the future? Int Dent J. 1997;47:247-58.

5- Ishikiriama A, Oliveira JF, Vieira DF, Mondelli J. Influence of some factors on the fit of cemented crowns. J Prosthet Dent. $1981 ; 45: 400-4$

6- Jörgensen KD. Factors affecting the film thickness of zinc phosphate cements. Acta Odontol Scand. 1960;18:479-90.

7- Kelly JR. Dental ceramics: current thinking and trends. Dent Clin North Am. 2004;48:513-30.

8- Kelly JR, Davis SH, Campbell SD. Nondestructive, threedimensional internal fit mapping of fixed prostheses. J Prosthet Dent. 1989;61:368-73.

9- Levine WA. An evaluation of the film thickness of resin luting agents. J Prosthet Dent. 1989;62:175-8.

10- Lorenzoni FC, Martins LM, Silva NR, Coelho PG, Guess PC, Bonfante EA, et al. Fatigue life and failure modes of crowns systems with a modified framework design. J Dent. 2010;38:626-34.

11- Miyazaki T, Hotta Y, Kunii J, Kuriyama S, Tamaki Y. A review of dental CAD/CAM: current status and future perspectives from 20 years of experience. Dent Mater J. 2009;28(1):44-56.

12- Mörmann WH, Bindl A, Lüthy $H$, Rathke A. Effects of preparation and luting system on all-ceramic computer-generated crowns. Int J Prosthodont. 1998;11:333-9.

13- Nakamura T, Dei N, Kojima T, Wakabayashi K. Marginal and internal fit of Cerec 3 CAD/CAM all-ceramic crowns. Int J Prosthodont. 2003;16:244-8.

14- Pettenò D, Schierano G, Bassi F, Bresciano ME, Carossa S. Comparison of marginal fit of 3 different metal-ceramic systems: an in vitro study. Int J Prosthodont. 2000;13:405-8.

15- Piwowarczyk A, Ottl P, Lauer HC, Kuretzky T. A clinical report and overview of scientific studies and clinical procedures conducted on the 3M ESPE Lava All-Ceramic System. J Prosthodont. 2005; $14: 39-45$.

16- Pjetursson BE, Sailer I, Zwahlen M, Hämmerle $\mathrm{CH}$. A systematic review of the survival and complication rates of allceramic and metal-ceramic reconstructions after an observation period of at least 3 years. Part I: Single crowns. Clin Oral Implants Res. 2007; 18:73-85.

17- Prakki A, Cilli R, Costa AU, Goncalves SE, Mondelli RF, Pereira JC. Effect of resin luting film thickness on fracture resistance of a ceramic cemented to dentin. J Prosthodont. 2007;16:172-8.

18- Rafferty BT, Bonfante EA, Janal MN, Silva NR, Rekow ED, Thompson VP, et al. Biomechanical evaluation of an anatomically correct all-ceramic tooth-crown system configuration: core layer multivariate analysis incorporating clinically relevant variables. J Biomech Eng. 2010;132:051001.
19- Rekow D, Thompson VP. Engineering long term clinical success of advanced ceramic prostheses. J Mater Sci Mater Med. 2007; 18:47-56.

20- Rekow D, Zhang Y, Thompson V. Can material properties predict survival of all-ceramic posterior crowns? Compend Contin Educ Dent. 2007;28:362-8.

21- Rekow ED, Harsono M, Janal M, Thompson VP, Zhang G. Factorial analysis of variables influencing stress in all-ceramic crowns. Dent Mater. 2006;22(2):125-32.

22- Rocha SS, Adabo GL, Ribeiro RF, Fonseca RG. Internal adaptation of cast titanium crowns. J Appl Oral Sci. 2007;15:24752.

23- Rossetti PH, Valle AL, Carvalho RM, Goes MF, Pegoraro LF. Correlation between margin fit and microleakage in complete crowns cemented with three luting agents. J Appl Oral Sci. 2008; 16:64-9.

24- Rudolph H, Luthardt RG, Walter MH. Computer-aided analysis of the influence of digitizing and surfacing on the accuracy in dental CAD/CAM technology. Comput Biol Med. 2007;37:579-87. 25- Rungruanganunt $P$, Kelly JR, Adams DJ. Two imaging techniques for $3 D$ quantification of pre-cementation space for CAD/CAM crowns. J Dent. 2010;38:995-1000.

26- Sailer I, Gottnerb J, Kanelb S, Hammerle CH. Randomized controlled clinical trial of zirconia-ceramic and metal-ceramic posterior fixed dental prostheses: a 3-year follow-up. Int J Prosthodont. 2009;22:553-60.

27- Sailer I, Pjetursson BE, Zwahlen M, Hämmerle $\mathrm{CH}$. A systematic review of the survival and complication rates of allceramic and metal-ceramic reconstructions after an observation period of at least 3 years. Part II: Fixed dental prostheses. Clin Oral Implants Res. 2007;18:86-96.

28- Scherrer SS, De Rijk WG, Belser UC, Meyer JM. Effect of cement film thickness on the fracture resistance of a machinable glass-ceramic. Dent Mater. 1994;10:172-7.

29- Scherrer SS, Mojon P, Belser UC, Meyer JM. The VITA HiCeram crown system: a clinical and laboratory investigation. J Dent Res. 1988;67:214

30- Thompson VP, Rekow DE. Dental ceramics and the molar crown testing ground. J Appl Oral Sci. 2004;12:26-36.

31- Tinschert J, Natt G, Mautsch W, Spiekermann H, Anusavice KJ. Marginal fit of alumina-and zirconia-based fixed partial dentures produced by a CAD/CAM system. Oper Dent. 2001;26:367-74.

32- Tuntiprawon M, Wilson PR. The effect of cement thickness on the fracture strength of all-ceramic crowns. Aust Dent J. 1995;40:17-21.

33- Wassermann A, Kaiser M, Strub JR. Clinical long-term results of VITA In-Ceram Classic crowns and fixed partial dentures: a systematic literature review. Int J Prosthodont. 2006;19:355-63. 34- Wiskott HW, Belser UC, Scherrer SS. The effect of film thickness and surface texture on the resistance of cemented extracoronal restorations to lateral fatigue loading. Int J Prosthodont. 1999;12:255-62. 